\title{
Production and Distribution of a Therapeutic Nutritional Product for Severe Acute Malnutrition in India: Opportunities and Challenges
}

\author{
KN BEESABATHUNI AND UCM NATCHU* \\ From PATH India, New Delhi; and *Pediatric Biology Centre, Translational Health Science and Technology Institute, National \\ Capital Region, India. \\ Correspondence to: Dr Uma Chandra Mouli Natchu, Pediatric Biology Centre, Translational Health Science and Technology \\ Institute, 496, Udyog Vihar Phase III, Gurgaon, National Capital Region, India. unatchu@thsti.org
}

\begin{abstract}
Limited resources for hospitalized treatment of India's nearly 8 million children with severe acute malnutrition (SAM) make community management of SAM a priority. Capability to produce sufficient quantities of Ready to Use Therapeutic Food (RUTF) is one component of preparedness for community management of SAM. Production of RUTF is a simple process that consists of grinding, mixing and packaging using widely available equipment. Nitrogen flush packaging increases shelf life to 2 years though it is the most expensive and slowest step of the production process. Being a therapeutic product, quality and safety must be ensured including aflatoxin measurement and estimation of micronutrient and macronutrient content consistently. RUTF can be made in India in several production models - (I) Dairy cooperatives and private manufacturers can produce large quantities to meet regional requirements, (ii) small and niche food manufacturers can produce smaller volumes but have a major presence in most parts of India; and (iii) "hand made" RUTF can be made by "village industries" for immediate local consumption. All the ingredients and equipment for RUTF are widely available in India - RUTF is already being produced in India for export. Concerns from various sections of society will need to be heard before community management of SAM using therapeutic, processed nutritional products can begin. Despite apprehensions about processed RUTFs or the sections of the public health community that press for its use, withholding alternative treatment for one of the largest killers of India's children must not be the option. It is time public health/ medical communities and civil society come together to make effective community management of SAM an immediate reality.
\end{abstract}

Key words: Distribution, India, Production, Ready to use Therapeutic food, Severe acute malnutrition.

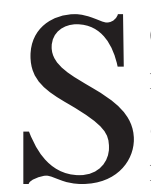

everely malnourished under-five children in India are estimated to constitute $6.4 \%$, in addition to $19.8 \%$ who are moderately malnourished according to the National Family Health Survey (NFHS) - 3(1). This translates to about 8.1 million children with severe acute malnutrition (SAM) in India. Currently available facilities for hospitalized care of children in India would be inadequate even if they were utilized exclusively for the treatment and rehabilitation of children with SAM(2). Limitations in availability as well as access to facility based care, therefore, make community management of SAM a priority. This would include screening and anthropometry of malnourished children, identification of those who can be managed without hospitalization and their nutritional rehabilitation and monitoring in their communities and homes. Small hospitals and facilities where children hospitalized with SAM are managed often lack kitchens where recommended diets to rehabilitate these children can be hygienically prepared every day. A ready to use therapeutic food (RUTF) product that can be administered to children with SAM in their homes or in small community facilities is, therefore, only one component of community management of SAM and the capability to produce RUTF is just one step in that direction.

\section{RUTF Production}

The production of RUTF is a simple process and 
consists of three basic steps - grinding, mixing and packaging(3). Typically, the ingredients used in the production of RUTF are milk powder, vegetable oil, peanuts, sugar, minerals and vitamins(3). Shelled groundnuts are roasted in a roaster at a temperature of approximately $160^{\circ} \mathrm{C}$ for $40-60$ minutes. This is followed by grinding them into smaller particle sizes in a grinder such as a hammer mill. Skimmed milk powder, the ground peanuts, vegetable oil, powdered sugar and the minerals and vitamins are then blended in a planetary mixer with less than $0.1 \%$ emulsifiers and anti-oxidants. The paste is then homogenized to further reduce particle size $(<200 \mu \mathrm{m})$ and is then packed. The shelf life of RUTF paste can be extended to 2 years by nitrogen-flush packaging, which has been shown to extend shelf lives of milk products(4). A production line with a rated capacity of 1.5 tonnes per day that includes a roaster, planetary mixer and a nitrogen flush packaging system is estimated to cost about 35-50 lakh rupees. Nitrogen flush packaging machinery is the most expensive component of an RUTF production line but paste that is not packed in airtight packages will need to be consumed within a few months, considerably limiting its utility, especially when storage and transportation is unpredictable. Nitrogen flush packaging is often the rate limiting step and will depend on the size of the pouches - larger pouches will hasten packaging but will be inappropriate for single day consumption by a single child. Particle size reduction machines such as pulverizers, hammer mills and universal grinders, mechanical mixers such as barrel mixers and planetary mixers and packaging machines are readily available for small batch production of 1 tonne per week and can be customized for higher output.

Lentils and rice have been used in alternative RUTF recipes but are yet to be well evaluated(5). Peanut butter is being produced in some parts of the country for export - peanut butter can also be directly sourced from such companies and used to prepare RUTF. This is very likely to increase cost and may be recommended for situations where machinery to grind peanuts into the size required is not available ("Hand made" RUTF).

\section{Quality ConTrol and Quality Assurance}

RUTF must be tested for aflatoxins - a major issue with peanuts, apart from testing for microbial contamination, heavy metals, pesticides, lipid oxidation, moisture content, fat and protein estimation, water activity and minerals or vitamins concentrations(6,7). If a mineral and vitamin premix from a certified supplier is added to RUTF, the concentration of one single vitamin or mineral can be estimated to ensure the quality and homogeneity of the product. This will reduce the costs associated with quality evaluation, including those related to the complexity of handling multiple laboratory instruments and analytical errors in estimating multiple micronutrient concentrations. When batch volumes are large, the frequency of testing also can be reduced bringing down costs further.

\section{Production Models of RUTF}

Self help groups and village industries: A number of food products that are current market leaders or favourites are made by self-help groups or village/ cottage industries (e.g. Lijjat Papad)(8). A number of such industries strive for societal good like gender equality, sustainability and poverty alleviation while producing very high quality food products(8). Often such companies are considered to be free of conflicting commercial interests. The ingredients will need to be provided in the form of ready to mix, preground ingredients for "hand mixing" in homes. This model is unlikely to result in large quantities of RUTF being produced in single batches. The cost of quality testing will be far higher since each small batch will need to be tested.

Dairy cooperatives: Beginning with the success of the Kaira District Cooperative Milk Producers' Union, the dairy cooperative movement has spread all over the country. Dairy cooperatives have also since diversified from milk into a range of food products like chocolates, baked goods and even oils(9). Amul, the brand of the Gujarat Cooperative Milk Marketing Federation and Mother Dairy, of the National Dairy Development Board, are among the top brands in India(10). Amul's sales and distribution network that reaches every corner of the nation is supported by the largest cold chain in the world and over 5 lakh retail outlets(9). Similarly, other cooperatives have popular brands (Mother Dairy, Vijaya, Aavin, and Verka) that rely on efficient and reliable distribution networks within each state. In addition to the necessary 
equipment and most (often all) ingredients being available in house, the distri-bution channels of these cooperatives will be invalu-able in making RUTF available across the country.

Niche food companies: A number of niche food companies exist all over the country that have held a major chunk of the market share for products like spices, traditional snacks, heat and serve foods and extruded products like pasta. Some of these companies have been participating in food fortification programs (Swagat Foods (P) Limited makes iron fortified rice premix using Ultra Rice ${ }^{\mathrm{TM}}$ technology). Others provide packaged foods for public health programs and clinical trials (Christy Friedgram Industry makes ready to use products for Integrated Child Development Scheme and double fortified salt for the mid day meal program in South India). Compact AS, a Norwegian company that manufactures therapeutic food products used by aid agencies, has commenced production of RUTF in India through its subsidiary, Compact India Pvt Ltd.

Large private food companies are capable of large-scale production of RUTF. Their volumes of production may support regional demands of RUTF. Doubts will be expressed about the business models of some of these companies. Strong, enforceable guidelines on marketing of RUTF and nontherapeutic modified RUTF-like products will be needed to limit the abuse of RUTF.

The scale of operations and the costs of production vary by the production model. Skimmed

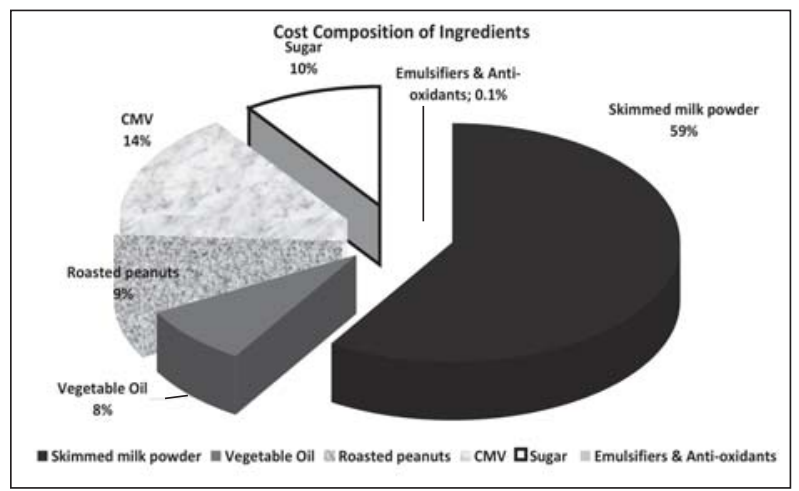

FIG. 1 Cost composition of ingredients required for RUTF production. milk powder accounts for nearly $60 \%$ of the ingredient costs (Fig 1). Hence milk cooperatives that produce skimmed milk powder will be ideally placed to produce cheaper RUTF with lower ingredient costs. Fixed costs account for a small proportion of the overall cost of RUTF production in models with specialized or customized equipment capable of producing 15 tonnes of RUTF per day (Fig 2). Fixed costs also account for a small percentage $(<3 \%)$ of the cost of RUTF for smaller companies capable of producing about 1.5 tonnes per day of RUTF on less specialized equipment. Nearly 80,000 metric tonnes of RUTF will be required to treat severely malnourished children in India with $300 \mathrm{~g}$ of RUTF per day for 30 days.

\section{OpPortunities FOR RUTF Production AND DISTRIBUTION IN INDIA}

Ingredients required for the manufacture of RUTF are readily available in India (Table I). India is the number one producer of milk in the world and over 1.6 lakh tonnes of milk powder is produced in India every year. Peanuts are ubiquitous in Indian diets and India is the largest exporter of shelled groundnuts in the world. Easy domestic availability of these ingredients with pre-existing distribution channels and local vendors keeps costs of these ingredients low unlike in Africa where the bulk of ingredients are imported. India is home to a large domestic food processing industry that deals in dairy foods, baked goods, heat and serve foods and spices that already use indigenously manufactured equipment that are required (or can be easily adapted) for the production

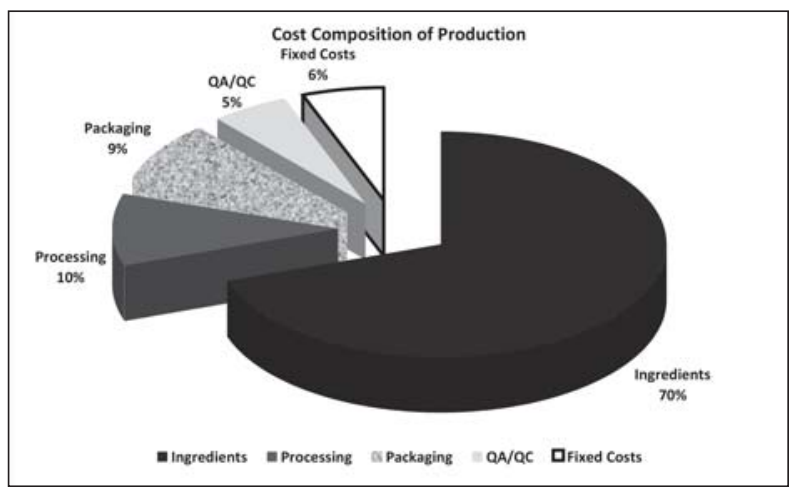

FIG. 2 Cost composition of RUTF production at production volumes of 15 tonnes per day. 
TABLE I Availability of Indigenous Ingredients for RutF Production in India(11,12)

\begin{tabular}{|c|c|c|c|}
\hline Commodity & $\begin{array}{l}\text { World production } \\
\text { rank }\end{array}$ & $\begin{array}{l}\text { Annual production } \\
\text { (in metric tonnes) }\end{array}$ & Exports \\
\hline Milk & 1 & 109 million & N/A \\
\hline Skimmed milk powder & 6 & 162,201 & $25 \%$ of annual production is exported \\
\hline Groundnuts & 2 & 9 million & $\begin{array}{l}\text { Largest exporter of shelled groundnuts - } \\
240,000 \text { tonnes }\end{array}$ \\
\hline Refined sugar & $\begin{array}{l}2^{\text {nd }} \text { largest producer } \\
\text { sugarcane }\end{array}$ & 26.3 million & $\begin{array}{l}3^{\text {rd }} \text { largest exporter at 2,261,228 metric of } \\
\text { tonnes }\end{array}$ \\
\hline
\end{tabular}

of RUTF. Bharat Immunologicals and Biologicals Corporation Limited (BIBCOL), a public sector company that manufactures vaccines and zinc tablets has developed a composite mineral and vitamin (CMV) formulation. This CMV, based on the WHO composition recommended for treatment of SAM, can be added directly as a premix to F-75, F-100, RUTF and other therapeutic nutritional products(13). This product is likely to be available for acceptability trials by the end of the year (personal communication). The entire spectrum of ingredients and equipment required for production of RUTF is indigenously available - RUTF made in India will therefore be a sustainable solution with local production that can vary from small to large-scale models in the public or private sector.

\section{Challenges to RUTF Production and DisTRIBUTION IN INDIA}

Severe acute malnutrition is almost always an illness that stems from the lack of sufficient food - few children get malnourished when sufficient quality food is available. The availability or the capability to produce RUTF does not address prevention of SAM or directly improve food security in these households. Irrespective of how reasonably indigenously produced RUTF is priced, it will remain beyond the purchasing power of most households where severe malnutrition occurs. For these children, RUTF will have to be provided by governments (local or central) or be channeled through non-profit and aid agencies. Therefore, the treatment of SAM, a condition arising from food insecurity, through commercial processed food is seen as a paradoxical, conflicting situation. It can be argued that some resources will be directed to procure RUTF that could possibly be used to improve access to food for these vulnerable sections of society through enhancements in employment, agricultural production, food rations or subsidized food. While this maybe true in part, the treatment of millions of severely malnourished children, many out of whom die everyday is as pressing a need as the prevention of further malnutrition through improved access to food. These therefore, must not be viewed as competing activities, much like the treatment of any other illness (e.g. Tuberculosis, HIV etc.) while concerted efforts are made towards preventing it.

Varied interpretations of the Supreme Court ruling on hot cooked meals have also led to confusion. The Supreme Court had ruled that hot cooked meals must be provided for children through the Integrated Child Development Scheme (ICDS) (14). This cannot be directly interpreted to preclude the use of food based therapeutic interventions for children who suffer from illnesses or the use of RUTF for children with SAM. Uncertainty about the support for community management of SAM based on RUTF will deter food companies from investing or venturing into RUTF production.

\section{THE WAY FORWARD}

Voices from various sections of society will need to be heard before a viable community management program can be effectively instituted for the management of SAM. The meeting organized on "Nutrition Therapy in SAM" at the All India Institute of Medical Sciences in November 2009 was a major step in this direction. A number of concerns raised against the use of RUTF are not characteristics of the product itself but seem to be directed against international or multinational agencies and corporations. While every voice of concern cannot be assuaged, considerable choice must be offered in production models and scales to fit the needs and 
views of market segments. Multiple producers and suppliers must be supported to prevent monopolization of the RUTF market. The Government and aid agencies (local and global) will remain the largest procurers of RUTF for children with SAM. In the absence of clearly stated governmental positions on the use of RUTF, few companies will be willing to produce RUTF for use in India. The fact that Compact India Pvt Ltd has established a production facility for RUTF and other nutritional products for SAM at Manesar, Haryana makes it unambiguously certain that RUTF can be produced in India on a large scale.

Most children with SAM cannot be accommodated in hospitals; many families cannot afford their earning members to stay with their children in hospitals for many weeks. Treatment in the homes of severely malnourished children provides a feasible solution in such scenarios. Efficacy trials will compare standard hospital care for SAM with community management; far removed from real life situations of limited care. Can we refuse to provide an alternative when we are unable to provide standard hospitalized care to millions of children with severe acute malnutrition?

\section{ACKNOWLEDGMENTS}

We acknowledge all vendors, suppliers and manufacturers who provided inputs for projections in this article. We also thank Mr Mukesh Juyal for helping with the manuscript preparation.

Contributors: KNB conceived, designed and conducted the analyses and interviews and prepared the manuscript. UCMN also designed the analyses and revised the manuscript for important intellectual content. All authors approved the final manuscript.

Disclaimer: All projections are based on data and costs obtained from vendors and food manufacturers in India. Since no data is available from companies that are actually already manufacturing RUTF, these are only estimates.

Funding: None.

Competing interests: None stated.

\section{REFERENCES}

1. International Institute for Population Sciences (IIPS) and Macro International. 2007. National Family Health Survey (NFHS-3), 2005-06: India: Volume I: 273.

INDIAN PEDIATRICS
2. Gupta P, Shah D, Sachdev HPS, Kapil U. National workshop on "Development of guidelines for effective home based care and treatment of children suffering from severe acute malnutrition”. Indian Pediatr 2006; 43: 131-139.

3. Manary MJ. Local production and provision of ready-to-use therapeutic food (RUTF) spread for the treatment of severe childhood malnutrition. Food Nutr Bull 2006; 27: S83-89

4. Lloyd MA, Hess SJ, Drake MA. Effect of nitrogen flushing and storage temperature on flavor and shelf-life of whole milk powder. J Dairy Sci 2009; 92: 2409-2422.

5. Bahwere P, Sadler K, Collins S. Acceptability and effectiveness of chickpea sesame-based ready-touse therapeutic food in malnourished HIV-positive adults. Patient Prefer Adherence 2009; 3: 67-75.

6. Peraica M, Radiæ B, Luciæ A, Pavloviæ M. Toxic effects of mycotoxins in humans. Bull World Health Organ 1999; 77: 754-766.

7. Okoth SA, Ohingo M. Dietary aflatoxin exposure and impaired growth in young children from Kisumu District, Kenya: Cross sectional study. Afr J Health Sci 2004; 11: 43-54.

8. Ramanathan M. Women and Empowerment: Shri Mahila Griha Udyog Lijjat Papad. Economic and Political Weekly 2004; 39: 1689-1697.

9. Welcome to Amul - The Taste of India. Available at: http://www.amul.com/products.html. Accessed June 3, 2010.

10. Synovate news. Available at: http:// www.synovate.com/news/article/extra/20070824/ Asia\%27s\%20Top\%201000\%20brands\%20 fact \%20sheet.pdf. Accessed June 3, 2010.

11. FAOSTAT, Food and Agricultural Organization of the United Nations. Available at: faostat.fao.org. Accessed May 2, 2010.

12. Hand Book of Sugar Statistics, Indian Sugar Mills Association, Ministry of Consumer Affairs, Department of Food \& Public Distribution, Govt. of India; 2009.

13. Management of Severe Malnutrition: A Manual for Physicians and Other Senior Health Workers. Geneva: World Health Organization; 1999.

14. Deshpande M, Dasgupta R, Baru R, Mohanty A. The case for cooked meals concerns regarding the proposed policy shifts in the mid-day meal and ICDS programs. Indian Pediatr 2008; 45: 445-449. 